\title{
A Study on Islamic Religion in Germany
}

\author{
Atilla Kurnaz \\ Department of German Language and Literature, Faculty of Arts and Sciences \\ Sakarya University, Sakarya, Turkey \\ E-mail: atillakurnaz@sakarya.edu.tr
}

\begin{abstract}
In this study, the position of Islamic Religious Education in the German education system is examined. In a country where Christianity is predominant, the history of Islamic Religious Education is not based on old. In Germany, where more than four million Muslims live, 800,000 Muslim students continue their education in schools. Muslims living in the country have their demands on teaching their religion to future generations and being German. After the German Islam Conference in 2006, Islamic Religious Education began to be a kind of movement in schools. According to Article 7 of the German Constitution, it is aimed to resolve the problem within the framework of religious freedom and the right to religious education. In the light of this study, it aims to provide a perspective on the problem of religion course applied to Muslim students in Germany today.
\end{abstract}

Keywords: Germany, Islam, Religious education, German Islam Conference

DOI: $10.7176 / \mathrm{JSTR} / 5-2-39$

\section{Almanya'da Uygulanan İslam Din Dersi Üzerine Bir İnceleme}

Özet

Araştırmada Alman eğitim sisteminde İslam Din Eğitimi’nin nasıl bir konumda olduğu incelenmiştir. Hristiyanlığın ağırlıklı olduğu bir ülkede İslam Din Eğitiminin geçmişi eskilere dayanmamaktadır. Dört milyondan fazla Müslümanın yaşadığı Almanya'da 800 bin Müslüman öğrenci okullardaki eğitime devam etmektedir. Ülkede yaşayan Müslümanlar dinlerini gelecek nesillere öğretilmesi ve bununda Almanca olması konusunda talepleri mevcuttur. Eyaletlerin İslam Din Eğitimi konusunda geçici çözümlerinin ardından 2006 yılında Alman İslam Konferansı'ndan sonra İslam Din Eğitimi bir nebze de olsa okullarda din dersi adına bir hareketlenme başladı. Alman Anayasası'nın 7. Maddesine göre din özgürlüğü ve din eğitimi hakkı çerçevesinde sorunun çözümlenmesi amaçlanmaktadır. Yapılan bu çalışma 1şı̆̆ında Almanya'da günümüzde Müslüman öğrencilere uygulanan din dersi sorununa bir bakış açısı sunmayı amaçlamaktadır.

Anahtar Kelimeler: Almanya, İslam, Din eğitimi, Alman İslam Konferansı

\section{Giriş}

Almanya'daki günümüz Müslüman toplumunun mevcudiyeti 60'lı ve 70'li yıllarında yaşanan işçi göçüne uzanmaktadır. II. Dünya Savaşı sonrasında ise batı Avrupa ülkelerinin hızlı ekonomik gelişmeleri ile bu ülkelerin emek piyasalarında duyulan gereksinimin karşılanabilmesi için İspanya, İtalya, Türkiye, Portekiz, Yugoslavya ve Kuzey Afrika ülkelerinden büyük miktarda, çalıştırmak amacıyla göçmen işçiler getirilmiştir (Gençler, 2004). Uluslararası göç arttı ve neredeyse bütün Kuzey ve Batı Avrupa emek göçünün ve sonrasında göçmen yerleşiminin sahası oldu.

İkinci Dünya Savaşından sonra yeniden ayağa kalkmaya çalışan Avrupa ülkeleri, işgücü oluşturmak için az gelişmiş ve gelişmekte olan ülkelerden göç kabul etmeye başlamasıdır. Savaşın ana aktörü olan ve Avrupa ülkelerin başında gelen Almanya, 1954-1970 yıllar arası Yunanistan, İspanya ve Türkiye gibi ülkelerden insan gücü alımı gerçekleştirmiştir. 
Yunanistan, İtalya, İspanya ve Portekiz uluslararası göç açısından diğer AB devletlerinden ayrı bir alt grubunu oluştururlar (Castles \& Miller, 2008). 1973'e kadar, göç veren ülkeler olarak görülüyorlardı fakat sonra farklı anlarda ve değişik aşamalarda, hem göç veren hem de göç alan önemli ülkeler haline geldiler. Bazı Avrupa ülkeleri 1970'li yılların sonlarına doğru göçü kontrol altına almaya yönelik önlemleri uygulamaya başlamışlardı. Fransa, İsveç, Hollanda, İngiltere ve başka Avrupa ülkelerinde yasal ve yasal olmayan yollardan kaynaklanan göçü kontrol etmeye ve kısıtlamaya yönelik tedbirler alınmıştır. Dokuz Avrupa ülkesinde 1960-1970 yılları arasında bulunan yabancı işçilerin sayısı 2.5 milyondan 5.4 milyona çıkarken, 1973'te 6.3 milyona çıkmış ve 1987'ye gelinceye kadar ise 5.8 milyona gerilemiştir (Gençler, 2004). 1960'lı yıllarda misafir işçi olarak gelen Müslümanlar; 70'li ve 80'li yıllarda ise aile birleşimiyle, 1990'lı yıllarda ise göç ve mültecilik yollarla Avrupa'ya yerleşmişlerdir. Elbette Avrupalı ülkelerin geçmişte sahip oldukları sömürgelerin de Müslüman nüfusun kıtada çoğalmasına neden olmaktadır. Fransa'daki göçmenlerin çoğu eskiden hüküm sürdükleri Cezayir, Tunus ve Fas gibi sömürgelerinden gelmektedir. Hollanda'daki Müslüman göçmenleri ise Endonezya'daki sömürge yıllarında gelenler oluşturmaktadır. İngiltere'deki Müslümanların birçoğunu da hem Pakistan hem de Bangladeş’teki insanlar oluşturmaktadır (Agentur der Europäischen Union für Grundrechte, 2006).

Avrupa'nın ucuz ve vasıfsız işgücüne ihtiyaç duymasından dolayı birçok insan kıtadaki ülkelere göç etmişlerdir. Yabancı bir ülkeye gelen göçmenler özellikle ülkenin başkenti veya çevresine ya da sanayinin gelişmiş olan şehirlere yerleşmişlerdir. Almanya'ya gelen Müslümanlar özellikle Berlin, Kuzey-Ren Vesfalya, Hamburg, Bavyera ve Frankfurt Hollanda'da ise Amsterdam, Rotterdam ve Utrecht'te yerleştikleri bilinmektedir. Bu durum Müslümanların ülkelerdeki belli yerlere yerleşmesine ve oradaki dini birlikteliğe neden olmaktadır (Agentur der Europäischen Union für Grundrechte, 2006).

1970'li yılların ortasında yaşanan ekonomik kriz, Avrupa ülkelerinde işçi alımlarının azaltılmasına ve daha sonrasındaysa durdurulmasına neden olmuştur. $\mathrm{Bu}$ yıllara kadar gelen işçilerin birçoğunun genç erkeklerden oluşması daha sonraki yıllarda ailelerini de yaşadıkları ülkelere aldırmalarıyla beraber farklı bir sosyal yapının da olmasına neden olmuştur. Oluşan bu sosyal yapıyla beraber Müslüman toplumunun hem sosyal hem de siyasal dinamiklerinde olumlu birer değişikliğe yol almıştır (Agentur der Europäischen Union für Grundrechte, 2006).

1980’li yıllarda Avrupa’ya gelen Müslümanların çoğu mülteci olarak gelenler oluşturmaktadır. Özellikle Afganistan, İran, Irak ve Lübnan'dan 90'lı yılların başındaysa Yugoslavya ve Somali'den gelmekteydiler. Bu göçmen ve mültecilerin birçoğu kalifiye insanlardan oluşmaktadır. Ayrıca Avrupa ülkelerine üniversite eğitimi için Müslüman öğrenciler de gelmekteydiler. Eğitim için gelenlerin sayıları işçi olarak gelenlere nazaran azda olsa eğitim durumları nedeniyle büyük rol oynamaktaydılar (Agentur der Europäischen Union für Grundrechte, 2006).

\section{Alman Eğitim Sistemi}

Almanya'da, her eyaletteki okul sistemi biraz farklıdır. Bütün çocuklar, genellikle dört yıl süren altı yaşında ilkokula devam ederler. Daha sonra, ortaokul, ortaokul veya lise gidip gelirlerse çocukların yararlarına karar verilir. Bir alternatif, tüm dereceleri yapabileceğiniz kapsamlı okuldur. Bazı federal eyaletlerde, ana ve ortaokullar da birleştirilir. Daha sonra bölgesel veya topluluk okulları denir.

Farklı okul türleri ve gerçekleştirme baskısı nedeniyle, Alman okul sistemi çok katıdır ve okulun ilk yıllarında okul kariyerinin belirlenmesi nedeniyle eleştirilmektedir. Çocuğunuzu bir Alman okuluna göndermek istiyorsanız, Alman okul sistemini iyi bildiğinizden ve çocuğunuzun geleceği için belirli bir okul türünü seçmenin sonuçlarını bildiğinizden emin olmalısınız (Justlanded, 2018).

\subsection{Almanya'da Din Eğitimi Hakkı}

Aydınlanmadan beri dinin eğitimdeki yerinin ayrılmaz bir parçası olup olmadığ konusunda tartışmalar devam etmektedir. Bu tartışmanın önümüzdeki kısa bir zamanda dahi son bulmayacağı hatta zaman zaman daha da şiddetleneceği varsayılmaktadır. Bir yandan dinin rasyonaliteyle bir alakasının olmadığını savunanlarla diğer taraftan dinin "ölümü” ile ilgili endişeler taşıyanlar arasında, dindar kişinin mi yoksa dindar olmayan bir kişinin mi daha aydın olacağı konusunu savunanlar arasındaki tartışmalar sürmeye devam edecektir. İki taraftan kimin argümanlarının daha kuvvetli olduğuna dair kesin bir muvaffakiyet bulunmamaktadır. Fakat akılcılık kavramı sadece matematik ve fen bilimleri ile sınırlandırılamaz bilakis diğer bilimlerle de akılcılık bağdaştırılabilinir. Akılcılık, örnek verilmesi gerekilirse estetik anlatımsalda müziğin, edebiyatın ve sanatın kullanılması ya da sembolik mantık içerisindeki hukuk, ekonomi ve toplumsal sorunların araştırılmasında da kullanılmaktadır. Örneklemek gerekirse bir biyoloji öğretmeninin bir gül hakkında yaptığı dersten yola çıkacak olursak biyoloji öğretmeni dersinde gülü tanıtırken veya hakkında bilgi verirken aynı zamanda edebiyat öğretmeni konumuna gelmiş olur. Edebiyat öğretmeninin anlatmış olduğu gül sembolü aşkı anlatmaktadır. Biyoloji öğretmeninin anlattığı gül ise sembol 
bakımından farklı bir şekilde de olsa aynı nesneyi yansıtmaktadır.

Din açısından bakıldığında ise şu anlam ortaya çıkmaktadır: dinin de dünya ile ilgili bir bakış açısı vardır. Kapsamlı bir eğitim sürecinin parçası olmasıyla birlikte dinin dünya erişiminin yapısı somut bir mezhep ya da din örneği içerisinde olasılıkları ve sınırları bilmeyi ve öğrenmeyi yansıtmaktadır.

Almanya'daki devlet ve dini cemaatler arasındaki ilişkiler 1919 yılındaki Weimar Cumhuriyeti Anayasasına dayanmaktadır. O zamanlarda alınan kararla devletin resmi bir dininin olmadığı ve devletdin işlerinin kesin bir çizgiyle ayrılmasına karar verilmiştir. Fakat dini cemaatlerin devlet ile işbirliğinde olmasına izin verilmiş hatta bu durum gerekli görülmüştür. Bu işbirliği esnasında devletin cemaatlere karş1 objektif davranması gerekmekteydi. 1968 yılında çıkarılan yasayla birlikte ülkede bulunan tüm okullar kamuya geçmiştir (Altun, 2001).

Devlet ile dini cemaatler arasındaki çalışmalar din eğitimini de kapsamaktadır. Avrupa'nın farklı ülkelerinde olduğu gibi cemaatlerin değil bilakis Alman devleti din eğitiminden sorumluluğa mükelleftir. Elbette Alman devleti dinin korunmasında ve/veya yayılması gibi görevleri yoktur fakat Alman Anayasasında din eğitimi konusunda maddenin olmasından dolayı devlet din eğitimini kamusal görev olarak görmektedir. Almanya'da din eğitimi mezhep temelli öğretim dalı olarak verilmektedir. Din eğitiminin verilmesi Alman Anayasası'nın 7. Maddesi'nin (Bundestag, 2018) koruması ve devletin denetimi altında bir haktır.

Almanya'daki din eğitimi mezhepsel temelli olmasından dolayı objektif ve bitaraf değildir. Bu demek değildir ki din derslerinde farklı dinler hakkında bilginin verilmediği; bilakis hangi din dersine öğrenciler katılırlarsa katılsınlar diğer dinler hakkında derslerinde öğretmenleri tarafından bilgilendirilmektedirler. $\mathrm{Bu}$ şekilde öğrencilerin hem kendi dinlerinde hem de farklı dinlerin ifade şekillerini veya sembollerini tanıma firsatı bulmuş oluyorlar. Ayrıca Almanya'daki din eğitimine kayıt veya kayıt sildirme konusunda serbesttirler. Mesela herhangi bir öğrenci ders esnasında öğrendiği bir konu hakkında tereddütte düştüğünde veya bir konunun kabul edilemez olduğunu düşündüğünde din dersinden kaydını sildirebilmektedir (ph-Freiburg, 2018).

\section{3 İslam Din Dersi}

Almanya'daki en büyük iki Hristiyan mezhepten sonra İslam dini en büyük üçüncü grubu olarak ülkede yerini almaktadır. Alman Uyum ve Göç Bakanlığı'na ( Bundesamt für Migration und Flüchtlinge) göre Almanya'da 4,4 ile 4,7 (bamf, 2018) milyon Müslümanın yaşadığı varsayılmaktadır. Bu rakam 82,2 milyonluk bir ülkenin \%5,4 ile \%5,7'lik bir kısmının İslam dinini benimsemiş olduğunu göstermektedir. Almanya'da yaşayan her 100 kişiden 5/6 kişinin Müslüman olması demektir. Almanya'da bulunan Müslüman nüfusunun çoğu 1960'dan sonra başlayan işçi göçü ile Almanya'ya gelen Müslümanlar oluşturmaktadır (Statista, 2018).

İslam dini Hristiyanlıkta da olduğu gibi farklı mezheplere ayrılmaktadır. Bu mezheplerin en büyüğünü Sünniler (2.640.000) oluşturmaktadır. Sünni grubu Aleviler (500.000) ve onları Şiiler takip etmektedir (225.500). Müslüman çocuk ve genç sayıları da aynı şekilde değerlendirilmektedir. Resmi rakamlara göre Almanya'daki Müslüman genç nüfus 850.000 olduğu tahmin edilmektedir. Bunların 650.000'inin okul çağında olduğu bilinmektedir ve bu rakam okula giden öğrencilerin \%7'sine tekabül etmektedir.

Almanya'da 1970'lerin sonuna doğru Kuzey-Ren Vesfalya eyaletinde İslam Din Eğitimi için çalışmalar görülmektedir. Aralık 1979 tarihinde Eyalet Enstitüsü (Landesinstitut) tarafından 1.-4. sınıflar için İslam din eğitimi müfredatı hazırlanmıştır (Uçar, 2006). Hazırlanan müfredata İslami cemaatler tarafından destek gelmeyince din dersi konseptinde değişiklik uygulayarak Müslüman öğrencilerin katıldığı anadil derslerine entegre etmek için müfredat hazırlamaya başlamıştır. Aynı şekilde Bavyera eyaletinde de 1986 yılında İslam din eğitimi anadil derslerinin içerisine konulmuştur. 2006 yılından önce İslami cemaatler ve Müslümanların istekleri doğrultusunda İslam din dersi konusu sesli şekilde dile getirilmeye başlanmıştır. Cemaatler ve dernekler Alman Anayasası'nın vermiş olduğu haklar ile birlikte bir çatı altında toplanıp İslam din dersinin okullarda resmi ders olması için başvuruda bulunmuşlardır (Pfaff, 2000). Almanya'nın hiçbir Eyaletinde Anayasa'nın belirtmiş olduğu 7. Maddenin 3. fikrasına göre devlet tarafından desteklenen bir İslam din dersi verilmemektedir. İslam din dersinin verilememesinin farklı nedenler sayılmaktadır. En önemli neden olarak ön plana çıkan durum ise Almanya'da yaşayan İslami toplumunun din dersinin içeriğinin hazırlanması konusunda tek bir muhatabın olmaması gösterilmekteydi. Nisan 2007 tarihinde "Muhataplık" konusunu faklı İslami cemaatler ve Alevi dernekler birleşerek aşmışlar ve "Çatı Örgütü” kurma konusunda hemfikir olmayı başarmışlardır. Bu kurumsallaşmadan sonra ise Müslüman cemaatlerin İslam din dersi istekleri konusunda başvuruları başlamıştır. Özellikle Sünni organizasyonlar Berlin, Baden-Würtemberg, Hessen, Kuzey-Ren-Vesfalya, Rheinland-Pfalz, Saarland ve Bremen eyaletlerinde İslam din dersi için başvuru yapmaya başlamışlardır. Aşağı Saksonya eyaletinde İslam din dersinin çerçevesi oluşturulmuş ve 1.-4. Sınıfları kapsayan müfredat örneği hazırlanıp sunulmuştur (Nibis, 
2018). Aynı şekilde 1980 yılından itibaren İslam din dersi için mücadele veren Berlin İslam Federasyonu'na (IFB) 13 Kasım 1998 (Jungefreiheit, 2018) tarihinde Berlin Federal İdari Mahkeme tarafından dini cemaat olarak tanımış ve 2000 yılından itibaren Berlin'deki okullarda İslam din dersi verme yetkisini vermiş bulunmaktadır. Bu tarihten önce Müslüman öğrenciler, özellikle Türk öğrenciler, Rheinland-Pfalz, Saarland, Schleswig-Holstein, Baden-Würtemberg, Hamburg, Aşağ1- Saksonya, Bremen, Berlin, Hessen ve Kuzey-Ren-Vesfalya eyaletlerinde seçmeli "Ana Dilde Eğitim" (Muttersprachlichen Ergänzungsunterricht) içerisinde İslam din dersi almaktadır. Bu derslerin verilme amacı olarak Almanya'da 1960'lı yıllarda başlayan işçi göçü ile birlikte ailelerini getiren işçilerin çocuklarının bir gün tekrar ülkelerine dönme olasılığını gütmektedir. Türkçe anadil eğitimi Almanya'da bulunan konsolosluklar üzerinden Türkçe olarak Türkiye'den gelen öğretmenler tarafından verilmekteydi. Müslüman olup da Türkçesi anadil olmayan Müslüman öğrenciler ise ya etik (Ethik) derslerine ya da eyaletlere göre Katolik veya Protestan (katholisch/evangelisch) din derslerine katılmaktaydılar. Geçmişte yaşanan bu durumlardan sonra okullarda verilen İslam din dersi Müslümanlar tarafından önemsenmekteydi. Bu önemsemenin sonucu olarak okullarda verilen İslam din derslerine katılım oranı \%85 düzeyine gelmiştir. Camilerdeki din dersine katılım ise \%15 olarak kalmıştır (Yılmaz, 2014). Veriler göstermektedir ki Alman eğitim kurumlarında verilen din dersleri hedefine ulaşmaktadır.

\subsection{Eyaletlere Göre İslam Din Dersi}

Almanya'da verilen İslam din derslerinin ilk yıllarında uygulanan İslam Bilim'i (Islamkunde) dersleri hiçbir şekilde Alman Anayasası'nın 7. Maddesinin 3. Bendinde yer alan:

“ Devlet okullarında verilen din dersi muntazam bir öğretim branşıdır. Devlet tarafından koruma altında olan din dersi cemaatlerin uygun gördüğü esaslara göre verilmektedir.”

açıklamayla örtüşmemektedir.

İslam din eğitiminin başlarda kendi başına okullarda okutulan bir branş dersi olmamasının başında Müslümanların bir dini cemaatinin (Religionsgemeinschaft) olmaması gösterilmektedir. Bir dönem de Ana Dil Derslerine (Muttersprachlicher Unterricht) entegre edilerek din dersi sorununa çözüm aranmıştır. Kuzey-Ren Vesfalya'da ise 1983 yılında İslam din dersinin verilmesi konusunda farklı dizaynlar uygulanmaya konulmuştur. 2003 yılında ise ilk olarak Alman Anayasası'nın din dersi hakkındaki görüşü okullardaki uygulanan pilot uygulamayla başlamıştır. Bu pilot uygulama ile birlikte ilk defa Müslümanlar için din eğitimi konusu Anayasa'ya uygun olarak sürdürülmeye başlanmıştır (Kiefer, 2005).

\subsubsection{Kuzey-Ren Vesfalya}

2012 yılında ilkokuldan başlayarak ortaöğretimde de İslam din dersi verilmesine başlanmıştır. Sayısal olarak bakıldığında hem öğrenci hem de okul olarak Kuzey-Ren Vesfalya başı çekmektedir. 110 okulun birinci sınıfından onuncu sınıfında kader verilen İslam Din Dersi okullarda 19.400 öğrenciye okutulmaktadır (Zeit, 2018).

\subsubsection{Aşağı Saksonya}

2003/04 yılında sekiz ilkokulla başlanan İslam Din Dersi 2005/06 yılında 19 ilkokula yükselmiştir (Bodenstein, 2008). 2018 yılında ise bu rakam 60 okula yaklaşmıştır. Eyalet genelinde 35 öğretmenin görev aldığı okullarda toplam 3.800 öğrenci İslam Din Dersine katılmaktadır (NDR, 2018).

\subsubsection{Bavyera}

2003/04 eğitim yılında bir ilkokulda pilot İslam Din Dersi eğitimine Erlangen şehrinde Erlangen İslam Topluluğu (Islamischen Religionsgemeinschaft Erlangen) ile birlikte başlanmıştır (Kiefer, 2005). Verilere bakıldığında 2016/17 eğitim yılında 400 okulda İslam Din dersine 11.000 öğrenci tarafından derslere katılım sağlanmaktadır(irp, 2018).

\subsubsection{Rheinland-Pfalz}

Eyalette 2004 yılından itibaren iki adet İslam Din Dersi modeli mevcuttur. Biri ilkokullarda diğeri ise ortaokullarda İslam Din Dersi modeli uygulanmaktadır. 30.000 Müslüman öğrencinin bulunduğu eyalette 12 ilkokul ve yedi ortaokulda (Religion-Bildung, 2018) İslam Din Dersi verilmektedir.

\subsubsection{Baden-Würtemberg}

2006/07 eğitim yılında pilot proje olarak on iki ilkokulda başlanan İslam Din Dersi eğitimi 2010 yılına kadar model olarak düşünülen ders 2018 yılına kadar hala kendine özgü bir branş olamamıştır. 2017/18 eğitim-öğretim yılında toplam 93 okulda toplam 5.900 öğrenci derslere katılmaktadır (Bildungsblick, 2018). 


\section{Sonuç}

Almanya ile Müslümanların tarihleri eski zamanlara dayanmaktadır. Fakat asıl Müslümanlarla iletişimleri ikinci dünya savaşı sonrasında yıkılan Almanya'da oluşan işçi ihtiyacının doğması ve 1960'lı yılların başında Türkiye'nin de aralarında bulunduğu Müslüman ülkelerle yapmış olduğu iş̧̧i anlaşmalarıyla meydana gelmiştir. Zamanla Almanya'ya yerleşen Müslümanların ailelerinin de bu ülkeye gelmesi ve çocuklarının okullara başlamasıyla birlikte ülkede yaşayan Müslümanların eğitim açısından dini eğitim talepleri dillendirilmeye başlanmıştır. Yıllarca İslam din eğitimi konusunda adım atılmayışı Almanya'daki Müslüman toplumunun çocukları din eğitimlerini camilerde almışlardır. 2006 yılında yapılan Alman İslam Kongresiyle birlikte ortaya çıkan Alman İslam Din Eğitimi fikriyle birlikte ülkede yaşayan 4,4 milyona yakın Müslümanın din eğitimi hakkına kavuşmuştur. Zorlu süreçler sonunda edinilen bu hak yeni olmakla birlikte gelişime açık görünmektedir. Bunun yanında Müslüman toplumun derse göstermiş olduğu ilgiyle birlikte önümüzdeki yıllarda hem öğrenci hem de öğretmen bakımında İslam din dersine ilginin artması beklenmektedir.

\section{Kaynaklar}

[1] Agentur der Europäischen Union für Grundrechte: Musime In Der Europäischen Union, 2006.

[2] Bundesregierung für Ausländerfragen: Islamischer Religionsunterricht an staatlichen Schulen in Deutschland. Praxis - Konzepte - Perspektiven, Dokumentation eines Fachgesprächs. Berlin 2000.

[3] Castles, Stephen ve Mark J. Miller, Göçler Çăğ - Modern Dünyada Uluslararası Göç Hareketleri, (Çev: Bülent Uğur Bal ve İbrahim Akbulut), İstanbul: İstanbul Bilgi Üniversitesi Yayınları, 2008.

[4] Gençler, Ayhan, Avrupa Birliği'nin Göç Politikası, Sosyal Siyaset Konferansları Dergisi, 2004

[6] Pfaff, Ulrich.: Islamische Unterweisung in Nordrhein-Westfalen. In: Die Beauftragte der Bundesregierung für Ausländerfragen: Islamischer Religionsunterricht an staatlichen Schulen in Deutschland. Praxis - Konzepte - Perspektiven. Dokumentation eines Fachgesprächs, Berlin 2000.

\section{İnternet Kaynakları}

[7 ] https://www.justlanded.com/deutsch/Deutschland/Landesfuehrer/Bildung/Das-deutscheSchulsystem, Erişim Tarihi: 14.12.2018.

[8] https://www.bundestag.de/parlament/aufgaben/rechtsgrundlagen/grundgesetz/gg_01/245122, Erişim Tarihi: 02.08.2018

[9] https://www.ph-freiburg.de/fileadmin/dateien/fakultaet3/theologie/pemselmaier/berufsprofil_religionslehrer_in-1.pdf, Erişim Tarihi: 08.01.2018.

[10] https://www.bamf.de/SharedDocs/Meldungen/DE/2016/20161214-studie-zahl-muslimedeutschland.html, Erişim Tarihi: 18.09.2018.

[11] https://de.statista.com/statistik/daten/studie/76744/umfrage/anzahl-der-muslime-in-deutschlandnach-glaubensrichtung/, ErişimTarihi: 10.01.2019.

[12] http://db2.nibis.de/1db/cuvo/datei/kc-iru-2010.pdf, Erişim Tarihi: 12.10.2018.

[13] http://jungefreiheit-archiv.de/archiv98/478aa15.htm, Erişim Tarihi: 20.01.2019.

[14] https://religion.bildung-rp.de/islamischer-religionsunterricht-erprobung.html, Erişim Tarihi: 16.08 .2018

[15] http://bildungsklick.de/pm/54443/ resonanz-auf-islamischen-religionsunterricht-istungebrochen-gross/i, Erişim Tarihi: 07.01.2019. 